\title{
UNA APROXIMACIÓN A LAS CARTAS DE RELACIÓN DE PEDRO DE ALVARADO: PROBLEMAS ECDÓTICOS Y DISCURSO CABALLERESCO
}

\author{
An Approach to the Letters of Relation by Pedro de Alvarado: Textual \\ Criticism Problems and Chivalric Discourse
}

José Luis Nogales Baena ${ }^{1}$

\begin{abstract}
RESUMEN
Las dos cartas de relación de Pedro de Alvarado retratan de modo ejemplar la voz de uno de los principales protagonistas de la "conquista" y, en concreto, el discurso legitimador de la conquista o invasión de Centroamérica. No obstante, sorprende el poco interés que han despertado en los estudios coloniales. Así pues, este trabajo se propone un primer acercamiento en detalle a ambos escritos desde una doble perspectiva: la ecdótica y el análisis discursivo. En la primera parte, tras un sucinto estado de la cuestión, se estudia el problema textual que se deriva de lo poco atendidas que han sido estas relaciones, poniendo el énfasis, sobre todo, en cuestiones de crítica textual. En la segunda, el análisis se centra en dilucidar los principales rasgos discursivos que se desprenden de los dos textos, para lo cual se parte de la noción de "autor semiculto" introducida por la lingüística italiana y del concepto de "discurso caballeresco" tal y como lo define José Antonio Mazzotti a partir de las reflexiones de Rolena Adorno. El objetivo final es subrayar la importancia de estos dos textos en el corpus colonial y la necesidad de una edición crítica que les haga justicia.
\end{abstract}

Palabras clave: Pedro de Alvarado, cartas de relación, estudios coloniales, discurso caballeresco, crítica textual

\begin{abstract}
The two letters of relation by Pedro de Alvarado exemplary depict the voice of one of the main protagonists of the "conquista" and, in particular, the legitimized discourse of the conquest or invasion of Central America. However, the little interest that they have aroused in colonial studies is surprising. Thus, this work proposes a first detailed approach to both writings from a double perspective: textual criticism and discursive analysis. In the first part, after a succinct examination of the state of the matter, I study the textual problem that derives from the lack of attention to these letters, placing emphasis, above all, on questions of textual criticism. In the second part, the analysis focuses on elucidating the main discursive features of the two texts, based upon the notion of autor semiculto ('semi-learned author) introduced by Italian linguistics, as well as upon the concept of "chivalric discourse," as it has been elaborated by José Antonio Mazzotti from Rolena Adorno's reflections. The final goal is to highlight the importance of these two texts in the colonial corpus and the need for a critical edition that would do them justice.
\end{abstract}

Keywords: Pedro de Alvarado, Letters of relation, Colonial studies, Chivalric discourse, Textual criticism.

\footnotetext{
${ }^{1}$ Boston University. Department of Romance Studies. Estados Unidos. Doctor en Estudios Filológicos por la Universidad de Sevilla. Teaching Fellow y PhD Candidate. Correo electrónico: joseluisnogales@ gmail.com
}

Recepción: 9/12/2018 Aceptación: 26/02/2019 


\section{Introducción ${ }^{1}$}

Las dos cartas de relación de Pedro de Alvarado que se conocen fueron escritas el 11 de abril y el 28 de julio de 1524: la primera, en Utlatán; la segunda, en la recién fundada Ciudad de Santiago. Se sabe que hubo otras dos anteriores relativas a la misma expedición, pero se perdieron en época temprana y apenas se tiene noticia de su contenido. ${ }^{2}$ Dicha expedición partió de México el 6 de diciembre de 1523 con Pedro de Alvarado como teniente de gobernador y capitán general, y fue ordenada por Hernán Cortés para descubrir y conquistar las tierras en torno a las ciudades de Utlatán y Guatemala, de las cuales los españoles habían tenido noticias que eran muy ricas y estaban muy pobladas. De ahí que las cartas vayan dirigidas a Cortés, quien, antes de partir, le había ordenado a Alvarado que le hiciese relación de sus avances. En sus propias palabras (“Cuarta relación”): “También encomendé al dicho Pedro de Alvarado tuviese siempre especial cuidado de me hacer larga y particular relación de las cosas que por allí le aviniesen para que yo la invíe a Vuestra Alteza” (Cortés, 1993, p. 495). En suma, a pesar del poco interés que ambos textos han despertado en los estudios coloniales, se trata del testimonio de uno de los principales protagonistas de la "conquista española" y, en concreto, del primer testimonio español de la conquista o invasión de Centroamérica desde Norteamérica, las tierras que actualmente corresponden al territorio

\footnotetext{
${ }^{1}$ Mi agradecimiento a los doctores José Antonio Mazzotti, Carmen de Mora Valcárcel y Jaime Marroquín por la lectura crítica que hicieron de este trabajo en las distintas fases de su formación.

${ }^{2}$ La existencia de estas dos cartas se deduce, por una parte, de una referencia en la "Cuarta relación" de Cortés, quien le explica a su majestad que había tenido nuevas de la expedición desde la provincia de Tehuantepec, al norte del actual estado de Chiapas (Cortés, 1993, p. 495), y, por otra, por el comienzo de la primera carta que se conserva de Alvarado, al inicio de la cual indica que había escrito anteriormente desde la provincia de Soconusco, al sur de Chiapas (Alvarado, 1954, p. 23). Véanse los comentarios de Gall al respecto (1968, pp. 72-73, 76).
} 
mexicano de Chiapas, Guatemala y El Salvador, y de lo que, en el periodo colonial, devino el Reino de Guatemala. ${ }^{3}$

Este trabajo se había planteado, inicialmente, un acercamiento a las cartas de Alvarado desde el paradigma actual de los estudios coloniales, esto es, tal y como se ha ido gestando esta materia desde los años ochenta, intercambiando las nociones de "autor" y "texto" por las de "sujeto" y "discurso". ${ }^{4}$ Ahora bien, a medida que se avanzaba en la investigación se halló que, previo al análisis del discurso y de la configuración del sujeto discursivo que lo sustenta, era fundamental repasar el estado de la cuestión y el problema textual que se deriva de lo poco atendidas que han sido estas relaciones. Es por eso que el artículo se divide, finalmente, en dos partes: una primera sobre lo que se ha hecho hasta ahora y lo que falta por hacer, con énfasis, sobre todo, en cuestiones de crítica textual que se consideran anteriores a todo tipo de análisis, y una segunda que se centra en los principales rasgos discursivos que se desprenden de los dos textos, para lo cual se parte de la noción de "autor semiculto" introducida por la lingüística italiana y del concepto de "discurso caballeresco" tal y como lo han elaborado Rolena Adorno y José Antonio Mazzotti en sus trabajos. Valga insistir en que ni una parte ni otra pretenden ser, en ningún caso, exhaustivas, sino, como indica el título, “una aproximación”, de modo que los problemas y particularidades señalados sirvan de aliciente para una edición crítica en condiciones y futuros estudios más detallados. ${ }^{5}$

\footnotetext{
${ }^{3}$ Recuérdese que la conquista de Centroamérica se lleva a cabo a un mismo tiempo, aunque ni mucho menos de forma coordinada, desde tres puntos distintos: México, Panamá y, en menor medida, las Antillas (arribando por la costa atlántica de Honduras) (Kramer, Lovell y Lutz, 1993, pp. 22-23, pero en general, pp. 21-40). Además de este trabajo recién citado, para una visión en detalle del contexto histórico y de las interpretaciones que se han hecho de la expedición de Alvarado, pueden verse, entre otros, los estudios de García (1987b, pp. 41-82), Lovell y Lutz (2001) y Restall y Asselbergs (2007).

${ }^{4}$ Véanse, por ejemplo, los trabajos de Mignolo y Adorno citados en la bibliografía.

${ }^{5}$ A este respecto, recuérdese también que el trabajo tiene su origen en una de las ponencias que se dictó en las I Jornadas Lengua y literatura en la colonia en Centroamérica: los discursos olvidados, entre los días 23 y 25 de mayo de 2018 en la Universidad de Costa Rica. A falta de otro lugar mejor para ello, mis agradecimientos a
} 


\section{Estado de la cuestión}

Tres son, en nuestra opinión, las posibles causas del desinterés que los estudiosos de distintos ámbitos han mostrado por las cartas de relación de Pedro de Alvarado. En primer lugar, el peso de la leyenda negra que envuelve a la figura histórica del conquistador. Leyenda que tiene, ciertamente, base real en muchos testimonios de la época, tanto españoles como indígenas (García, 1985; Restall y Asselbergs, 2007), pero que no parece haber sido suficientemente revisada desde una perspectiva crítica moderna, ni debería, en cualquier caso, ser una traba para el estudio de los textos.

En segundo lugar, cabría aducir la falta de "valor literario" de las cartas que, desde el punto de vista de la "literatura colonial", le habría restado valor estético a estos escritos. Indudablemente, las cartas de Alvarado pueden llegar a ser decepcionantes leídas desde un punto de vista literario, sobre todo si se comparan con las de Cortés o con algún otro modelo de relación epistolar culto de la época. Así, se ha dicho que "las cualidades del conquistador de Guatemala parecen haber estado en campos muy ajenos a las narraciones históricoliterarias" (Gall, 1968, p. 74), como si fuese eso lo que se hubiese propuesto su autor, o que “el estilo de Alvarado es monótono y cansino” (García, 1985, p. 109), entre otras opiniones que podrían citarse. ${ }^{6}$ Mas a esto cabría objetar que depende del punto de comparación adoptado - por ejemplo, desde el punto de visto de lo oral en lo escrito, las cartas de Alvarado presentan un testimonio excepcional-, además de que, como se ha demostrado, la crítica estética es inadecuada como método para estudiar las letras coloniales (Adorno, 1988, p. 24).

la organización por haber contado conmigo, especialmente al director del evento, el doctor Alexánder Sánchez Mora.

${ }^{6}$ Gall también afirma que las relaciones de Alvarado "giran alrededor de la matanza, lo demás es cosa superficial contada de manera escueta. El estilo es demasiado lacónico, sin ímpetu, redactado sin mayores detalles" (1968, pp. 74, 76). Ferro, de forma similar, que "la relazione della marcia di conquista è una scarna e monótona enumerazione di vittorie seguite da massacri, appropiazioni e distruzioni” (1998, p. 87). 
Por último, y se unen aquí los dos factores anteriores, cabría decir que las cartas de Alvarado han quedado a la sombra de las de Cortés, ofuscadas por su éxito, pues el conquistador de México alcanzó una fama y notoriedad inmediata mucho mayor que la de su compañero de armas, y esto en muy diversos aspectos, incluido el literario.

En este sentido, debe destacarse la labor de García Añoveros a mediados de los ochenta, quien, consciente del vacío historiográfico en que había caído la figura de Pedro de Alvarado, publicó en esa década varios trabajos dedicados a ahondar en el estudio del personaje (véase García en la bibliografía citada). De ellos, mención particular merece su investigación "Don Pedro de Alvarado: las fuentes históricas, documentación, crónicas y bibliografía existente" (1987a), ya que al reunir las fuentes disponibles sobre el conquistador, así como las escritas de su propia mano, facilita la tarea de los futuros investigadores que quieran adentrase en el corpus textual relativo al que fuese gobernador de Guatemala.

Sin embargo, los aportes a partir de esas fechas no han sido numerosos. Con alguna que otra salvedad, entre las que debe citarse el libro de José María Vallejo García Hevia (2008) dedicado a los juicios de residencia contra Pedro de Alvarado, siguen sin aparecer monografías sobre el autor y, particularmente en el ámbito de los estudios coloniales, apenas ha habido tres o cuatro acercamientos a sus cartas de relación: los trabajos de Donatella Ferro (1998; 1999), María Tenorio (2002) y Elba Magaña Morton (2009). De estos cuatro, los dos estudios de la primera autora son los más consistentes, aunque se posicionan todavía en una visión muy apegada al estudio de los textos como "literatura". Basado en las definiciones de Walter Mignolo sobre los escritos de la conquista (1982), y teniendo en cuenta las cartas de relación de Cortés, Ferro (1997) trata de definir tipológicamente las dos relaciones de Alvarado, al paso que comenta el contenido de los dos escritos y el estilo del autor. Dos años 
después, y a raíz de ese primer trabajo, dedica un segundo artículo a la traducción al italiano que de las cartas de Alvarado hizo Juan Bautista Ramusio, cuya primera publicación vio la luz en Venecia en 1555.

El artículo de Tenorio tiene la particularidad de ser el primero que se centra en los textos de Alvarado - no solo las cartas, también otros escritos- desde el punto de vista de los estudios coloniales actuales. Esto es, estudia a su autor como sujeto y el contenido de varios de sus textos como discurso. A partir de ahí, utilizando las ideas de Bajtín en La cultura popular en la Edad Media y en el Renacimiento, su propósito es analizar "la corporeidad material del sujeto construido en el discurso". El planteamiento es interesante, pero los ejemplos analizados muy pocos. El artículo es, de hecho, muy breve y, a falta de más ejemplos por analizar, las conclusiones no son iluminadoras. ${ }^{7}$

La tesis doctoral de Magaña, consciente de lo poco estudiada que había sido la figura del conquistador y los escritos de los contemporáneos que versaban sobre él, "intenta", según se indica en la introducción, “examinar la vida de Pedro Alvarado, su personaje revelado en sus propias palabras, y vistas, entendidas y analizadas por sus contemporáneos, y por modernos escritores de la conquista española en el Nuevo Mundo” (2009, p. 9). Empero, los resultados de esta investigación son, cuando menos, dudosos, entre otras razones: por la falta de documentación, la superficialidad con que comenta algunos escritos -comentarios que

\footnotetext{
${ }^{7}$ He aquí el último párrafo del trabajo de Tenorio: “Al examinar el anclaje material de las acciones corporales del conquistador, referidas en sus papeles, se ha intentado atisbar la violencia intrínseca del proceso de conquista de estas tierras. Al beber, al comer, al fornicar, el cuerpo de Pedro de Alvarado desplaza o niega otros cuerpos, otros cuerpos que activamente lo niegan o lo desplazan a él, lo hieren. El conquistador lo tiene bien claro: hay que pasar por encima de los cuerpos, desplazarlos, sacarlos del camino con la espada, destriparlos con los caballos, quemarles sus ciudades, esclavizarlos y negarles su agencia, someterlos. Para afianzar su autoridad y emerger como figura, para afirmarse como servidor de su majestad, 'conquistador', debe negar y oscurecer, borrar y desplazar a los cuerpos otros, cuya sangre habría de dejar señalada esa tierra que, llámese Guatemala o El Salvador, se insertó en los anales de la historia occidental bajo el signo de la violencia, bajo la rúbrica de una siempre inacaba e imperfecta conquista" (2002, párr. 22).
} 
devienen paráfrasis-, la redacción desigual, y lo inconsistente de sus argumentos y conclusiones. $^{8}$

En resumen, en lo que se refiere a las cartas y documentos de Pedro de Alvarado que se conservan, queda aún mucho trabajo por hacer. Nadie se ha ocupado aún con suficiente ahínco de sus dos cartas de relación, objeto de estudio del presente trabajo, que se plantea más como una "aproximación" que como un estudio definitivo, entre otras cosas, por los problemas de tipo filológico que se comentarán a continuación. Igualmente, no se ha confrontado el discurso de Alvarado con los discursos indígenas que se han conservado de la invasión a Guatemala -especialmente, con el llamado Memorial de Sololá-, o el modo en que se configura el sujeto de Alvarado en sus escritos y esos textos indígenas con otras narraciones de la época. Más aún, sería de interés estudiar la forma en que, paralelamente a la configuración de la leyenda negra del personaje, se forja también una imagen cuasimitológica de él, especialmente en uno de los historiadores criollos más importantes del Reino de Guatemala, el controversial Francisco Antonio de Fuentes y Guzmán, quien dedicó una parte importante de su Recordación Florida a la figura de Alvarado. Por otro lado, y antes de adentrarse en el estudio de los textos, es imprescindible recalcar la falta de ediciones filológicamente fiables para llevar a cabo el análisis. Es una cuestión que no debe sorprender a nadie, pues al haber sido las cartas de relación desatendidas por la literatura colonial y la historiografía, los filólogos no se han ocupado de editar el texto convenientemente, y esta

\footnotetext{
${ }^{8}$ Por ejemplo, Magaña afirma, y en ello se basan después sus análisis, que "las obras escritas por Pedro de Alvarado consisten en dos cartas a Cortés, tres cartas al ayuntamiento de Guatemala, y su propia defensa en los cargos impuestos en contra de él" (2009, p. 31), lo cual es completamente equívoco. Véase el trabajo de García Añovero (1987a, pp. 251-252), quien documenta siete cartas más otros dieciocho documentos suscritos por él (la mayoría sobre sus expediciones), además de la documentación relativa a las causas que se le imputaron; aunque, stricto sensu, estos documentos no fueron "escritos" -ni dictados- por él. Para otros ejemplos de las fallas señaladas, se remite a los comentarios de las cartas de relación que se estudian en este trabajo (2009, pp. 34-43).
} 
afirmación sirve para el resto de escritos conservados del conquistador. Cierto es que las cartas de relación, en concreto, se han seguido reeditando hasta tiempos recientes, pero nunca en las condiciones adecuadas, pues existen varios testimonios, impresos y manuscritos, que no han sido nunca cotejados. ${ }^{9}$

Las cartas fueron impresas apenas un año después de ser escritas: el 20 de octubre de 1525, en Toledo, junto a la Cuarta relación de Cortés y otra carta de Diego de Godoy. ${ }^{10}$ Como señaló Delgado, es probable que el editor, Gaspar de Ávila, decidiese añadir las relaciones de Alvarado y Godoy para engordar el volumen, pues la Cuarta relación es de menor extensión que las dos que se habían impreso previamente (1993, p. 72). ${ }^{11}$ Una segunda edición de este libro fue impresa en Valencia el 16 de julio de $1526 .{ }^{12}$ A su vez, si bien los originales se han perdido, se conservan dos copias manuscritas de las relaciones en los mismos códices en que se han conservado las cartas de relación de Cortés y Godoy: son los denominados Códice de Viena y Códice de Madrid (Delgado, 1993, pp. 64-70). ${ }^{13}$ Aunque no

\footnotetext{
${ }^{9}$ Para una lista parcial de las ediciones modernas y sus traducciones desde el siglo XVIII hasta mediados del siglo XX, puede consultarse la entrada que le dedica Simón Díaz (1973) a Pedro de Alvarado. A ella habría que sumar, como mínimo, la transcripción que hace Gall de la primera carta usando el Códice de Viena (1968, pp. 77-89), una edición en 1967 (Alvarado, 1967), otra en 1979 (Alvarado, 1979) y una más en 1993 (Alvarado, 1993); las de 1967 y 1993 reeditadas en más de una ocasión (ciertamente, no se ha podido consultar el libro de 1993, sino la tercera edición: Alvarado, García y Ciudad-Real, 2000, pp. 17-32). También hay una nueva traducción al inglés (Restall y Asselbergs, 2007, pp. 27-47), de gran valor por los comentarios y notas que la acompañan.

${ }^{10}$ El escribano Diego de Godoy formó parte de otra expedición enviada por Cortés hacia el sur a finales de 1523, la encargada de conquistar Chiapas, la cual estuvo a cargo de Luis Marín (Schmidt Riese, 2003, pp. 2425). Sobre su relación, escrita probablemente a mediados de junio de 1524 (Schmidt Riese, 2003, pp. 58-59), pueden verse ahora los comentarios de Schmidt-Riese (2003, pp. 44-46, 58-63), así como la edición diplomática que preparó a partir del Códice de Viena (pp. 95-109).

${ }^{11}$ Se apunta aquí a la Segunda y Tercera relaciones, publicadas por Jacobo Cromberger en 1522 y 1523 , respectivamente; recuérdese que la Primera y la Quinta no fueron descubiertas y publicadas hasta el siglo XIX (Delgado, 1993, pp. 71-73).

${ }^{12}$ Para este trabajo, se han consultado los ejemplares que de estos dos libros se conservan en la biblioteca John Carter Brown. El de 1525 ha sido digitalizado y está en acceso abierto en la web. Véase Cortés 1525 y 1526 en la bibliografía.

${ }^{13}$ El primero, Codex Vindobonnensis, se conserva en la Österreichische Nationalbibliothek con las siglas S. N. 1600, pero se puede consultar en edición facsímil (Cortés, 1960). El segundo lo custodia la Biblioteca Nacional de España, sigla 3020, ha sido digitalizado y está en acceso abierto en la web (Cortés, ca.1527?).
} 
se sabe con seguridad, estos manuscritos son, probablemente, transcripciones directas de los originales, al menos en el caso de las cartas de Cortés (Delgado, 1993, pp. 68-69), pero no hay razones para pensar que no lo sean también de las de Alvarado. Comentando los escritos de Cortés, Delgado afirma que ambos códices son independientes, pues el de Madrid “aporta datos que faltan en el de Viena" (1993, p. 69). Además, su cotejo de las ediciones impresas y de los manuscritos demuestra que existen variantes importantes entre unos y otros, lo mismo que existen variantes en el caso de las cartas de relación de Alvarado, según hemos podido comprobar al realizar unas cuantas calas de prueba.

En definitiva, un trabajo de cotejo y anotación de variantes, como se ha hecho con los textos de Cortés, se presenta como una tarea imprescindible para la reconstrucción fidedigna de las cartas de Alvarado. Aún más, por trabajoso que sea, para seguir el criterio filológico más riguroso sería importante tratar de cotejar todas o el mayor número de copias impresas conservadas, a fin de ver si en el proceso de impresión se introdujeron variantes, práctica común en la época (Moll, 2000, p. 25). Por el contrario, todas las ediciones que se han hecho hasta la fecha, con la excepción de Gall (1968, pp. 77-89), que publicó una versión paleográfica modernizada de la primera carta en el Códice de Viena, se han realizado a partir de la impresión de 1525 o de alguna otra que ni siquiera es especificada, lo cual dio lugar a malentendidos y equivocaciones. Es el caso, por ejemplo, de la edición de la Biblioteca de Autores Españoles (Vedia, 1852, pp. 457-462, con varias reediciones) o la de José Valero Silva (1954), las cuales reproducen los títulos de tipo descriptivo que le dio a ambas cartas el académico Andrés González de Barcia más de dos siglos después (González, 1749, pp. 157, 161). Esto es, a pesar de lo que pueda creerse, esos epígrafes no son los que se le dieron en las impresiones del siglo XVI. En 1525 y 1526 las cartas solo llevaban los siguientes 
encabezados, respectivamente: "Relación hecha por Alvarado a Hernando Cortés” y "Otra relación hecha por Pedro de Alvarado a Hernando Cortés”. Fue González de Barcia quien en la primera mitad del siglo XVIII compuso los más largos y luego repetidos por muchos: "Relación hecha por Pedro de Alvarado a Hernando Cortés, en que se refieren las guerras y batallas para pacificar las provincias de Chapotulan, Checialtenengo y Utlatan, la quema de su cacique, y nombramiento de sus hijos para sucederle, y de tres sierras de acije, azufre y alumbre" y "Relación hecha por Pedro de Alvarado a Hernando Cortés, en que se refiere la conquista de muchas ciudades, las guerras, batallas, traiciones y rebeliones que sucedieron, y la población que hizo de una ciudad; de los volcanes, uno que exhalaba fuego, y otro humo; de un río hirviendo, y otro frío; y cómo quedó Alvarado herido de un flechazo". De González de Barcia los tomó la Biblioteca de Autores Españoles, ya que reproduce, modernizado, el texto que fijó este otro; y de la Biblioteca los tomó Valero Silva, quien se limita a seguir este otro texto; pero en ninguna de las dos ediciones se encontrará comentario alguno respecto a esto. $^{14}$

Por todas estas razones, es necesaria una edición filológica de las cartas de relación de Alvarado. No se han cotejado nunca los ejemplares antiguos conservados, ni se han explicado jamás asuntos fundamentales como las reglas de modernización o puntuación empleadas en la transcripción; por no hablar de la falta de una anotación coherente que aclare también problemas lingüísticos. El trabajo de análisis discursivo que sigue a continuación, como cualquier otro análisis de tipo textual que se haga o se haya hecho hasta la fecha de estos textos, queda sujeto, por tanto, a las posibles flaquezas o inconsecuencias del texto de estudio. En cualquier caso, a la espera de una edición crítica en condiciones, todas las referencias que

\footnotetext{
${ }^{14}$ De la Biblioteca de Autores Españoles toma el texto también (sin señalarlo en ningún lugar) la edición de 1979, introduciendo aún otras modernizaciones y cambios tipográficos.
} 
siguen corresponden a la edición de Valero Silva de 1954, tanto por agilizar este trabajo como por facilitarle a los lectores interesados la localización de las citas (por lo mismo, se elimina el año en las referencias y se deja tan solo el número de página). Se han compulsado las citas extensas con el Códice de Viena y la edición de 1525 y, aunque se han encontrado algunas variantes, no se han anotado porque ni alteran en lo esencial nuestros argumentos ni creemos que este sea el lugar adecuado para ello.

\section{Pedro de Alvarado y el discurso caballeresco}

Como se mencionó, las cartas de Alvarado han sido menospreciadas por su estilo y lenguaje en comparación con otros textos canónicos de la conquista, especialmente al compararlas con las de Cortés. Consideramos que una de las razones principales por la que esto sucede es por la incapacidad de Alvarado de reproducir exitosamente el tipo discursivo que está tratando de seguir -al menos en su forma más elaborada por la tradición culta- el de la carta de relación o carta relatoria, cuyas exigencias retóricas y estructura fundamental se conformaban según el modelo epistolar de la época (Mignolo, 1982, p. 67). ${ }^{15}$ Es decir, Alvarado no es un "experto" en la práctica de la escritura, en la producción de textos, sino, más bien, lo que la lingüística italiana ha definido como "autor semiculto": un autor de escasa cultura, "sin formación literaria y sin práctica en el oficio de escribir" (Oesterreicher, 1994, p. 158, quien reconoce igualmente que el término, por su amplitud, incluye muchas gradaciones; véase también Oesterreicher, 2004, p. 734). Así, en las cartas de relación de

\footnotetext{
15 "Carta relatoria" es como la llama Mignolo (1982, pp. 57-59), quien describe este tipo de textos y el modo en que se conforman. Véase, en general, Mignolo (1982, pp. 57-69) para su definición de "tipo discursivo" y sus comentarios sobre las cartas relatorias. En el resto de este trabajo se usa siempre el término "cartas de relación", como se hace con los textos de Cortés, pues se considera más establecido. Pueden entenderse ambos como sinónimos.
} 
Alvarado son evidentes ciertos rasgos de oralidad propios de la inmediatez comunicativa: disposición y trato irregular de la materia narrada; repetición de palabras y expresiones fijas, entre las que destaca el uso abusivo del pronombre 'yo'; uso excesivo de la conjunción 'y' para encadenar frases y largos periodos, a pesar de que en la época fuese práctica común; anacolutos; inconsistencia en el uso de la primera persona, que vacila entre el plural y el singular de manera incoherente, etc.

Para quien no haya leído las cartas de Alvarado, características como el uso abusivo del pronombre 'yo' o el de la conjunción ‘y’ pueden recordarle a las cartas de Cortés, en las que estas palabras se repiten también con frecuencia. Sin embargo, se trata de un asunto distinto. Es cierto que Cortés se dibuja también en sus cartas como protagonista prominente y cuasiúnico de sus hazañas (Kruger Hickman, 1987, pp. 147-150), como lo hace Alvarado, pero no se trata aquí de una cuestión de contenido, sino a una serie de características estilísticas de las que no se ha hecho más que enumerar unas cuantas de forma muy genérica -en un estudio más detallado podrían indicarse muchas otras siguiendo el listado de rasgos universales de lo hablado y de variantes diatópicas, diastráticas y diafásicas que enumera Oesterreicher (2004, p. 736)-: todas sumadas es lo que nos permite definir al conquistador de Guatemala como autor semiculto. En fin, no hay espacio en este trabajo para detenerse en un estudio comparativo de los estilos de Cortés y Alvarado, pero valga recordar que lo que en uno ha sido valorado como una gran estrategia narrativa de persuasión (véase, por ejemplo, la tesis de Kruger Hickman, 1987, en particular, pp. 147 y ss.) o ha sido objeto de comparación, por ejemplo, con la prosa de Julio César o la estética de Juan de Valdés (Alcalá, 1950, pp. 133-147); en el otro, por excesivamente repetitivo y desestructurado, ha dado lugar a los comentarios negativos que ya se han expuesto (supra, n. 5). Por otra parte, tampoco es 
el objetivo de este estudio, en este momento, comentar todos los rasgos de oralidad que se aprecian en las dos cartas de relación estudiadas, sino tan solo aquellos que se consideran más relevantes para definir al sujeto discursivo que se desprende de ellas.

Por ejemplo, en lo que se refiere a la estructura, es evidente que el autor ha tratado de seguir un modelo similar en ambas cartas, es posible que siguiendo una serie de preguntas especificadas por Cortés previamente ${ }^{16}$ grosso modo, el siguiente: saludo, justificación de las contiendas, descripción de las batallas, descripción del paisaje, peticiones a Cortés, despedida. En cualquier caso, la estructura encaja, en sus líneas principales, con el modelo epistolar de la época, heredero de la Edad Media: salutatio, exordium, narratio, petitio, conclusio. Empero, esta estructura está insuficientemente delimitada en el texto y es a veces contradictoria: hay digresiones exageradas y no se ofrece la misma importancia a los distintos tipos de información. Alvarado se explaya, verbigracia, en los detalles de las batallas, pero presta poca atención a la descripción del paisaje, las tierras que descubre o los individuos que las pueblan. Igualmente, se reiteran persistentemente las advertencias que dice hacerles a los indígenas, lo que justifica las posteriores batallas y las tomas de esclavos, un punto que se ahondará más adelante.

Con todo, uno de los rasgos más significativos en cuanto a la voz discursiva es el de la inconsistencia que se da en el uso de la primera persona, el cual pasa del singular al plural sin transición alguna. Este es uno de los rasgos más marcados de la oralidad y la falta de rigor con que fueron escritas estas cartas: la vacilación del sujeto discursivo entre un 'yo' que ‘ordena', ‘juzga', ‘ve', 'dirige', ‘sentencia' o 'funda ciudades'; y un 'nosotros’ que 'lucha',

\footnotetext{
${ }^{16}$ La posibilidad, muy acertada, de que Alvarado esté contestando a cuestiones específicas dadas por Cortés previamente, fue sugerida al investigador de este estudio por el profesor Jaime Marroquín Arredondo, y es una idea que aquí solo se apunta, pero que habría que estudiar más en detalle teniendo en cuenta el contexto de la época. Véase sobre el asunto: Barrera Osorio (2006, pp. 81-91).
} 
'avanza' y 'se defiende' todos a una. Por supuesto, no se trata de un rasgo de estilo conscientemente buscado. La tendencia de Alvarado es a imponerse como sujeto único de la narración, como protagonista exclusivo de la expedición. Como si hubiese viajado solo, Alvarado usa el singular para exponer acciones que inexcusablemente incluían a un grupo mucho más amplio: "Y aquí estuve dos días corriendo la tierra, y a cabo de ellos me partí para otro pueblo llamado Quezaltenago, y aqueste día pasé dos ríos muy malos, de peña tajada" (p. 26). No obstante, es su inconsistencia en la escritura la que le traiciona y revela el contingente de hombres que con él marchaban. Tras lo recién citado, sigue: "Y allí hicimos paso con mucho trabajo, y comencé a subir un puerto" (p. 26). La presencia del plural aumenta significativamente en las descripciones de las batallas, pero no elimina nunca la percepción protagónica del yo singular. A modo de ejemplo:

Salieron obra de tres o cuatro mil hombres de guerra sobre una barranca, y dieron en la gente de los amigos y retrajéronla abajo, y luego los ganamos; y estando arriba recogiendo la gente para rehacerme, vi más de treinta mil hombres que venían $a$ nosotros, y plugo a Dios que allí hallamos unos llanos, (...), los esperamos, hasta tanto que llegaron a echarnos flechas y rompimos en ellos; (...), y hicimos un alcance muy bueno, y los derramamos, y murieron muchos de ellos, y allí esperé toda la gente, y nos recogimos, y fuíme a aposentar una legua de allí a unas fuentes de agua (pp. 2627; énfasis propio). ${ }^{17}$

Junto a este uso abusivo de las formas singulares en primera persona para acciones realizadas por grupos, lo que bien podrían describirse como el antónimo del plural de modestia, son remarcables las repeticiones del pronombre 'yo', otro rasgo de oralidad que

\footnotetext{
${ }^{17}$ Hay muchos más ejemplos. Para la segunda carta, véanse especialmente las pp. 36-37.
} 
insiste al mismo tiempo sobre el protagonismo que el sujeto discursivo se otorga -recuérdese el "carácter egocéntrico" que tradicionalmente se le ha atribuido al discurso oral (Serrano, 2014, p. 325, con referencias a la bibliografía previa)-. Por ejemplo, en la primera carta: Y como me vieron pasado a lo llano, se arredraron no tanto, que yo no recibí mucho daño de ellos, y yo lo disimulaba todo, por prender a los señores, que ya andaban ausentados; y por mañas que tuve con ellos, y con dádivas que les di para más asegurarme, yo los prendí (p. 29; énfasis propio).

Y de forma similar en la segunda, cuando se dirige a los pobladores de Utlatán, que estaban siendo acosados por los de la ciudad de Atitlán:

Y yo les respondí que yo los enviaría a llamar [a los de Atitlán] de parte del Emperador nuestro señor; y que si viniesen, que yo les mandaría que no les diesen guerra ni le hiciesen mal en su tierra, como hasta entonces lo habían hecho; donde no, que yo iría juntamente con ellos a facerles la guerra y castigarlos (p. 36; énfasis propio).

Más aún, Alvarado no habla como representante de su ejército o sus soldados, sino como señor o capitán de ellos. Se trata de un sujeto que posee las tropas bajo su mando y que distancia a su persona de ellas constantemente. De este modo, dice: "Mis mensajeros, yo venía (...) a conquistar y pacificar [o] que de mí y de los españoles de mi compañía serían muy favorecidos" (pp. 23-24; énfasis propio). ${ }^{18}$ Y, en la segunda carta: "Hice alarde de toda mi gente de pie y de caballo" (p. 24), o "me hirieron muchos españoles, y a mí con ellos” (p. 42).

\footnotetext{
${ }^{18}$ El último ejemplo puede dar lugar a confusión, pero todo apunta a que en él "compañía" tiene el mismo significado que le da Covarrubias en su tercera acepción, la de "los soldados que militan debajo de un capitán" (1611, p. 587), igual que al final de la primera carta, donde Alvarado escribe de nuevo: "La gente de españoles de mi compañía de pie y de caballo" (pp. 31-32).
} 
A todo lo anterior cabe añadir la gran carencia de nombres propios en las cartas. Este déficit podría contrastarse, como otras cuestiones, con la mayor frecuencia de nombres que aparecen en las cartas de Cortés, pero, sobre todo, debería compararse con textos mucho más cercanos al de Alvarado, tanto en sus circunstancias como en su estilo y objetivo, como es el caso de la carta de Diego de Godoy impresa también en los volúmenes de 1525 y 1526. De hecho, en la primera carta solo se encuentra un nombre y no tiene ningún protagonismo, pues simplemente le sale al paso a Alvarado al explicarle a Cortés por qué no le envió el azufre que había encontrado: "Y por enviar a Argueta y no querer esperar, no envío a vuestra merced cincuenta cargas de ello" (p. 31). ${ }^{19}$ En la segunda aparecen cuatro nombres, pero son todos de capitanes, y esto porque el conquistador de Guatemala explica cómo distribuyó sus fuerzas y las órdenes que dio cuando no podía combatir por haber sido herido. Además, cabe añadir que tres de estos capitanes eran sus hermanos -Jorge, Gonzalo y Gómez de Alvarado--, mientras que el cuarto, Pedro Portocarrero, su hombre de confianza y futuro yerno (Lovell y Lutz, 2001, p. 49). ${ }^{20}$

En fin, se han apuntado hasta aquí algunos de los rasgos del sujeto discursivo que las marcas de oralidad dejan vislumbrar. Alvarado se presenta como sujeto protagonista cuyo ‘yo' inunda toda la narración. El 'nosotros' no parece más que un uso involuntario, cuya alternancia con el 'yo' es incoherente y propia de un registro escrito poco cuidado. Estos pocos ejemplos bastan para demostrar la falta de técnica escritural del conquistador, quien

\footnotetext{
19 José Valero Silva apunta a pie de página que “debe de tratarse del conquistador de México Hernando de Argueta" (p. 31, n. 16).

${ }^{20}$ En cualquier caso, no debe tomarse este dato como algo excepcional, pues era común la implicación de grupos familiares en la empresa de la conquista. Lo apuntan Restall y Asselbergs (2007): "Conquest companies were often family affairs (Francisco Pizarro took three of his four brothers with him when he invaded the Inca Empire), and the Alvarado company was no exception; Pedro's comrades included his three brothers and three cousins" (p. 8).
} 
parece haber tenido un conocimiento muy básico de las fórmulas y de los recursos retóricos escritos de su época. En estas cartas todo es traslúcido, llano y directo: el interés del conquistador por justificarse, su visión protagónica y egocéntrica del mundo, incluso sus peticiones a Cortés al final de cada una, que evitan todo formulismo y van directas al grano. ${ }^{21}$ Muy al contrario de las conocidas relaciones de Cortés, cuya intención y sinceridad han sido tan discutidas por la crítica - véase, verbigracia, la revisión que Kruger Hickman (1987) hace de la conocida lectura de Beatriz Pastor en Discurso narrativo de la conquista de América (pp. 32 y ss.)-, no parece quedar espacio para ambigüedades o sentidos ocultos en frases tan directas como las que al final de la segunda carta le dirige Alvarado a su superior, recriminándole que no haya informado al rey de sus logros (pp. 47-48): "Y de esto nadie tiene la culpa sino vuestra merced [le dice] por no haber hecho relación a su majestad de lo que yo le he servido" (p. 47).

Cabe destacar que, al carecer del aparataje retórico de otros textos, las cartas de Alvarado se presentan como una especie de "producto en bruto" del principal discurso de la conquista. Nos referimos a lo que el profesor José Antonio Mazzotti, siguiendo a Rolena Adorno, denomina, "por comodidad operativa", "el discurso caballeresco" (2011, pp. 102-104), en el cual se refleja el pensamiento caballeresco y cristiano forjado en la Edad Media: una serie de

\footnotetext{
${ }^{21}$ Restall y Asselbergs (2007) han sugerido la posibilidad de que Alvarado escribiese sus cartas pensando en que podrían llegar a ser publicadas en el futuro (p. 23); no es imposible, pues fue práctica común en la época, pero no se hallan pruebas suficientes en el texto para apoyar dicha hipótesis. Es más, pensamos que la hipótesis de Restall y Asselbergs (2007) surge, en parte, de una lectura errada del inicio de la primera carta de Alvarado, la cual traducen como "Sir, / From Soconusco I wrote to Your Majesty", y anotan: "Alvarado addresses this letter to the king ('Your Majesty') although it is written to Cortés; he probably had both men in mind as his audience, as well as the larger public of the literate elite back in Spain, hoping that his campaign would lead to (and be received as) another triumph like that of defeat of the Mexica" (p. 27). Sin embargo, no hay tal "Majestad" en la carta, tanto en la edición de 1525 como en la de 1526 -al menos en los dos ejemplares consultados- se lee claramente "vuestra merced", y a "vuestra merced" corresponden también las abreviaturas de los dos manuscritos. Se trata, pues, de la misma fórmula con la que Alvarado se dirige repetidamente a Cortés a lo largo de ambos textos, sin que quepa interpretar aquí ningún doble sentido.
} 
categorías que impregnaron la mentalidad medieval y sirvieron para justificar la expansión de la Corona en América tras el periodo de la Reconquista, y cuyo tema abarcador era la cultura y la práctica de la guerra, así como la idea de expandir la religión cristiana. ${ }^{22}$ A este respecto, valga insistir que el concepto de "discurso caballeresco" no se refiere a una manifestación literaria en el discurso de los conquistadores, sino, como ya se ha dicho, a una serie de categorías que impregnaron la mentalidad medieval y sirvieron para justificar la expansión de la Corona en América tras el periodo de la -así llamada- Reconquista. Esas categorías se registran en un corpus textual más amplio que el puramente literario -cuyo exponente máximo, en época de Alvarado sería el Amadís de Gaula-, incluyendo, entre otros, los tratados de caballerías medievales que escribieron Alfonso X, Raimundo Lulio y el Infante Juan Manuel (Mazzotti, 2011, pp. 102-104; 2017). ${ }^{23}$ Entre los máximos representantes de ese discurso, con sus diferencias y matizaciones, Mazzotti cuenta las cartas de Hernán Cortés y la Historia de Bernal Díaz. Entre medio, como pieza indispensable en la reconstrucción de ese discurso, habría que situar las cartas de Pedro de Alvarado. ${ }^{24}$ Para demostrarlo, se comentarán varios términos e ideas clave que se repiten en sus textos, por más que esto suponga regresar a algunos tópicos frecuentes en los escritos sobre el Nuevo

\footnotetext{
${ }^{22}$ Además del artículo recién citado de Mazzoti, pueden verse al respecto: Adorno (1990); Mazzotti (2017). Es conocido por todos que la idea de un discurso caballeresco se remonta a trabajos anteriores, como el libro de Ida Rodríguez Prampolini, Amadises de América (1948), o el de Leonard Irving, Books of the brave (1949), incluso otros precedentes. Sin embargo, estas tesis han sido matizadas por los cambios de perspectiva acaecidos en los estudios coloniales durante la segunda mitad del siglo XX. Para una revisión: "Los libros del conquistador de Irving A. Leonard: aportes y legados" (Adorno, 2008, pp. 119-155).

${ }^{23}$ Conviene recordar que el texto de Alfonso X es el Título XXI de la Partida Segunda; partida que tuvo por ello una pronta difusión, y que se editó frecuentemente, ya en el siglo XV, de forma independiente (Juárez y Rubio, 1991, pp. 18-19).

${ }^{24}$ Ya en 1954 José Valerio Silva señalaba, con buen olfato crítico, que "la manera de ser" de Alvarado "estaba impregnada de un estilo caballeresco, cosa muy característica entre los hombres de su siglo", y que eso se nota, por supuesto, en el contenido de su carta (p. 15).
} 
Mundo. Lo que interesa destacar aquí, precisamente, es la llaneza con que queda expuesta esta serie de ideas inherentes al discurso de la conquista.

Por ejemplo, toda la sección inicial de la primera carta conservada es sintomática de esa mentalidad caballeresca a la que se ha hecho referencia, contiene muchos motivos que se repiten y desarrollan más adelante:

Y después de haber enviado mis mensajeros a esta tierra, haciéndoles saber cómo yo venía a ella a conquistar y pacificar las provincias que so el dominio de su majestad no se quisiesen meter, y de ellos como a sus vasallos, pues por tales se habían ofrecido a vuestra merced, les pedía favor y ayuda por su tierra, que haciéndolo así, que harían como buenos y leales vasallos de su majestad, y que de mí y de los españoles de mi compañía serían muy favorecidos y mantenidos en toda justicia; y donde no, que protestaba de hacerles la guerra como a traidores rebelados y alzados contra el servicio del Emperador nuestro señor, y que por tales los daba; y demás de esto, daba por esclavos a todos los que a vida se tomasen en la guerra (pp. 23-24).

Nótese la estratificación social que permea el discurso de Alvarado, harto conocida. Se trata de un orden establecido durante la Edad Media en Europa, y que el conquistador se siente obligado a instaurar y defender en las nuevas tierras conquistadas: en la cima, el "Emperador nuestro señor”; en lo más bajo, los vasallos, que deben someterse a su servicio; en el medio, como ejecutor y protector de ese orden, él y sus soldados. Si los vasallos cumplen con el emperador serán "favorecidos y mantenidos en toda justicia", si no serán tratados como "traidores rebelados y alzados" y, en consecuencia, reducidos a esclavitud. Tal es el esquema, repetido en varias ocasiones en sus cartas (pp. 36, 41, 44), que le sirve para justificar las conquistas, las matanzas y la toma de esclavos; esquema que responde, como es evidente, a 
los principios jurídicos defendidos en la época por personalidades como Juan López de Palacios Rubios, y que habían dado lugar al texto del "requerimiento", ${ }^{25}$

El suyo es, pues, el discurso de la ley y el orden, de la autoridad y la verdad. Alvarado actúa en nombre del emperador (p. 37), y esto le permite castigar o perdonar:

Y luego vinieron y se pusieron en mi poder; y yo les hice saber la grandeza y poderío del Emperador nuestro señor, y que mirasen que por lo pasado yo en su real nombre lo perdonaba, y que de allí adelante fuesen buenos, y que no hiciesen guerra a nadie de los comarcanos, pues que eran todos ya vasallos de su majestad (pp. 37-38).

Le permite, asimismo, actuar desde una posición moral superior que, a diferencia de los indígenas, conoce lo que está bien o mal y puede predicarle estos valores en tono paternalista: "Y mandé que fuesen de ahí adelante buenos" (p. 39), “y les rogué que fuesen buenos" (p. 41), "yo envié mis mensajeros a los señores de allí a decirles que no fuesen malos" (p. 44), etc. Además, existe, sin tapujos, un espíritu de conquista que solo se justifica en el servicio a la Corona: "Y deseando calar la tierra y saber los secretos de ella, para que su majestad fuese más servido, y tuviese y señorease más tierras, determiné de partir de allí” (p. 39).

A todo ello ha de sumarse la fe religiosa del caballero, igualmente convencido de que Dios está de su parte y de que es él quien le guía y ayuda en sus batallas y conquistas. Por ejemplo: "Y plugo a Dios que allí hallamos unos llanos" (p. 26), “y pienso, con el ayuda de nuestro Señor, presto lo atraeremos al servicio de su majestad" (p. 31), "y otro día de mañana nos encomendamos a nuestro Señor, y fuimos por la población adelante” (p. 37), etc. La fe religiosa de Alvarado es tal, que llega a solicitar a Cortés que organice una profesión en su ayuda:

\footnotetext{
${ }^{25}$ La bibliografía sobre este tema es enorme. A modo de síntesis, puede verse, por ejemplo: Zavala (1947).
} 
Que estamos metidos en la más recia tierra de gente que se ha visto; y para que nuestro Señor nos dé victoria, suplico a vuestra merced mande hacer una profesión en esa ciudad de todos los clérigos y frailes, para que nuestra Señora nos ayude, pues estamos tan apartados de socorro, si de allá no nos viene (p. 32).

En este contexto, no sorprende que Alvarado se dirija a los indígenas como a infieles: “Sino que Dios nuestro Señor no consiente que estos infieles hayan victoria contra nosotros" (p. 28), lo que entronca con la mentalidad de la lucha contra los musulmanes, la filosofía de la conquista de América y la justificación de batallas y matanzas en el continente (a modo de síntesis puede verse: Zavala, 1947, pp. 24-41). Este es un tema sobre el que giraron los grandes debates legislativos y religiosos en la península y sobre el que insistieron los cronistas de Indias. Recuérdese la famosa afirmación de Francisco López de Gómara en la dedicatoria de su Historia general de las Indias (1552) a Carlos V: "Comenzaron las conquistas de indios acabada la de moros, porque siempre guerreasen españoles contra infieles" (López, 1979, p. 8).

Además, todo se hace por la Corona, pero también por los méritos que se espera recibir a cambio. El de Alvarado, como el de todos, según estaba establecido desde época medieval, es un discurso que espera recibir frutos de su trabajo en forma de honra, títulos y dinero. Al final de la última carta informa que "la gente de españoles de mi compañía de pie y de caballo lo han fecho tan bien en la guerra que se ha ofrecido, que son dignos de muchas mercedes” (pp. 31-32). Y un poco más abajo, tras pedirle que hagan una procesión para recibir ayuda divina en su conquista, añade: “También tenga vuestra merced cuidado de hacer saber a su majestad cómo le servimos con nuestras personas y haciendas y a nuestra costa; lo uno para descargo de la conciencia de vuestra merced, y lo otro para que su majestad nos haga 
mercedes” (p. 32). Todos estos reclamos se vuelven más agrios en la segunda carta, cuando el conquistador de Guatemala le recrimina a Cortés no haber informado al rey de sus logros.

Es a partir de estas últimas recriminaciones, sobre todo, que se ha querido ver en los escritos de Alvarado una especie de competencia no declarada con Cortés (Valero, 1954, p. 16). Desde luego, se debe tener en cuenta, como anotan Restall y Asselberg (2007), que los efectos de la herida que sufrió el conquistador en su lucha con los pipiles parecen evidentes en la acritud con que está redactada la segunda relación conservada (p. 42). Recuérdese que Alvarado escribe en este mismo texto:

Que me dieron un flechazo que me pasaron la pierna, y entró la flecha por la silla, de la cual herida quedé lisiado, que me quedó una pierna más corta que la otra bien cuatro dedos; y en este pueblo me fue forzado estar cinco días para curarnos (p. 42).

Algo sobre lo que vuelve a insistir en las peticiones finales: "Y cómo en su servicio [el de su majestad] me han lisiado de una pierna" (p. 47). En este sentido, es posible que frases como las siguientes no solo deban leerse a título informativo de los méritos obtenidos, sino como una demostración personal de las capacidades que el teniente de gobernador y capitán general se asigna con respecto a su superior, fruto igualmente de su mal humor:

Que, según soy informado, es la ciudad [de la provincia de Tlapallan] tan grande como esa de Méjico, y de grandes edificios, y de cal y canto, y azoteas; y sin esta, hay otras muchas (...) [e] y crea vuestra merced que es más poblada esta tierra y de más gente que toda la que vuestra merced hasta agora ha gobernado (pp. 46-47).

Con todo, un punto más debe resaltarse sobre estas comparaciones que hace Alvarado, y es que estén dirigidas o no a demostrarle a Cortés lo que él es capaz de hacer, demuestran un cambio de referente en la mentalidad de la conquista o, en otras palabras, la consolidación 
verbal de una realidad. Esto se ve más claramente en la primera carta, donde parece más difícil aducir una competición entre uno y otro. Cuando Alvarado indica: "Y allí me aposenté y estuve reformándome y corriendo la tierra, que es tan gran población como Tascalteque [Tlaxcala], y en las labranzas ni más ni menos, y friísima en demasía” (p. 27), se observa que el conquistador, cuya cultura letrada parece haber sido más bien escasa, no necesitaba ya de leyendas o comparaciones con España o Europa, sino que tenían un nuevo punto de referencia para describir la realidad americana, la que habían conocido durante la conquista de México.

\section{Conclusiones}

Resumiendo, las cartas de Alvarado muestran un sujeto egocéntrico y protagónico, cuyo pensamiento encaja punto por punto con el discurso caballeresco elaborado en la Edad Media y perpetuado durante la conquista de América. Sin gozar del manejo de la retórica que demuestra Cortés, y careciendo igualmente del detallismo y la prolijidad narrativa de Bernal Díaz, estos dos textos se muestran imprescindibles en la reconstrucción del discurso caballeresco por la inmediatez con que parecen haber sido concebidos y escritos, con lo cual se muestra el pensamiento caballeresco de uno de los protagonistas principales de la conquista. En relación con esto, la carencia de una formación letrada más amplia no le impide a Alvarado convertirse en un exponente importante de esta mentalidad. Las nociones de bien y mal que maneja el conquistador, la convicción de que lucha contra infieles y de que la Corona y la Iglesia tienen privilegio sobre esas tierras a priori, la estratificación social en que piensa el mundo, o la confianza en que Dios y el rey recompensarán sus actos en el cielo y en la tierra son algunos de los rasgos principales de este discurso. Alvarado es retratado también como un sujeto semiculto, cuyo uso de la tradición textual a la que quiere acoplarse, 
la de las cartas relatorias, es más bien rudimentario. Los rasgos de oralidad que se cuelan en su escritura permiten ver al trasluz su persona y las categorías que ordenan su pensamiento, así como el modo en que se iba configurando en los conquistadores la realidad del Nuevo Mundo.

\section{Referencias bibliográficas}

Adorno, R. (1988). Nuevas perspectivas en los estudios literarios coloniales hispanoamericanos. Revista de Crítica Literaria Latinoamericana, 14(28), 11-28. https://doi/10.2307/4530388

Adorno, R. (1990). La construcción cultural de la alteridad: El sujeto colonial y el discurso caballeresco. I Simposio de Filología Iberoamericana. Zaragoza, España: Libros Pórtico.

Adorno, R. (2008). De Guancane a Macondo: Estudios de Literatura Hispanoamericana. Sevilla, España: Renacimiento.

Alcalá, M. (1950). César y Cortés. México: Editorial Jus.

Alvarado, P. (1954). Relación hecha por Pedro de Alvarado a Hernán Cortés, en que se refieren las guerras y batallas para pacificar las provincias del antiguo reino de Goathemala. Estudio y notas de José Valero Silva. México: José Porrúa e Hijos.

Alvarado, P. (1967). Muerte de Pedro de Alvarado: Cartas de relación de Alvarado a Hernán Cortes. Guatemala: Editorial José Pineda Ibarra.

Alvarado, P. (1979). Cartas de relación de Alvarado a Hernán Cortés. En VV. AA., Muerte de Pedro de Alvarado (pp. 93-122). Guatemala: Editorial José de Pineda Ibarra. 
Alvarado, P. (1993). Cartas de relación: Pedro de Alvarado a Hernán Cortés. San Salvador, El Salvador: Dirección Nacional de Patrimonio Cultural, Consejo Nacional para la Cultura y el Arte.

Alvarado, P., García Palacio, D. y Ciudad-Real, A. (2000). Cartas de relación y otros documentos. Nota introductoria de Pedro Escalante Arce. San Salvador, El Salvador: Dirección de Publicaciones e Impresos, Consejo Nacional para la Cultura y el Arte.

Barrera Osorio, A. (2006). Experiencing Nature the Spanish American Empire and the Early Scientific Revolution. Austin, EE. UU.: University of Texas Press.

Cortés, H. (1525). La quarta relacion q[ue] Ferna[n]do Cortes gouernador y capitan general porsu majestad enla Nueua España d[e]l mar oceano embio al muy alto [y] muy potentissimo inuictissimo señor don Carlos emperador semper angusto [sic] y rey de España nuestro señor: enla qual estan otras cartas [y] relaciones que los capitanes Pedro de Aluarado [y] Diego Godoy embiaron al dicho capitan Fernardo [sic] Cortes. Toledo, España: impreso por Gaspar de Ávila. https://archive.org/details/laquartarelacion00cort

Cortés, H. (1526). La quarta relacio[n] que Ferna[n]do Cortes gouernador y capita[n] general por su magestad enla nиеиа España del mar oceano e[m]bio al muy alto [y] muy potentissimo inucitissimo señor don Carlos emperador semper agusto y rey d'Spaña n[uest]ro señor.: enla qual estan otras cartas y relaciones quelos capitanes Pedro de Aluarado e Diego Godoy embiaron al dicho capitan Fernardo Cortes. Valencia, España: impreso por George Costilla.

Cortés, H. (ca.1527?). Relaciones de Hernán Cortés al Emperador Carlos V. Mss/3020. http://bdh.bne.es/bnesearch/detalle/bdh0000037293. 
Cortés, H. (1960). Cartas de relación de la conquista de la Nueva España: Escritas por Hernán Cortés al Emperador Carlos $V$ y otros Documentos relativos a la conquista, años de 1519-1527; Codex Vindobonensis S. N. 1600. Introducción y bibliografía de Charles Gibson. Estudio codicológico de Franz Unterkircher. Graz, Austria: Akademische Druck / U. Verlagsanstalt.

Cortés, H. (1993). Cartas de relación. Edición, introducción y notas de Ángel Delgado Gómez. Madrid, España: Castalia.

Covarrubias Orozco, S. (1611). Tesoro de la lengua castellana o española. Edición integral e ilustrada de Ignacio Arellano y Rafael Zafra. Madrid, España: Universidad de Navarra, Iberoamericana. https://archive.org/details/tesorodelalengua00covauoft

Delgado Gómez, Á. (1993). Introducción. En H. Cortés (1993), Cartas de relación (pp. 7102). Edición, introducción y notas de Ángel Delgado Gómez. Madrid, España: Castalia.

Ferro, D. (1998). Le Relaciones di Pedro de Alvarado conquistador del Guatemala. Studi di Letteratura Ispano-Americana, 31, 81-93.

Ferro, D. (1999). 'Di Pietro d'Alvarado a Fernando Cortese': Le 'Lettere' di Pedro de Alvarado nella raccolta ramusiana: alcune osservazioni sui modi del tradurre. Studi di Letteratura Ispano-Americana, 32, 7-24.

Gall, F. (1968). La Primera Relación conocida de Pedro de Alvarado. Anales de la Sociedad de Geografia e Historia de Guatemala, 41(1), 62-93.

García Añoveros, J. M. (1985). Pedro de Alvarado, capitán de hernán Cortés. Aproximaciones y diferencias. Quinto Centenario, 9, 107-26. 
García Añoveros, J. M. (1987a). Don Pedro de Alvarado: las fuentes históricas, documentación, crónicas y bibliografía existente. Mesoamérica, 13, 243-282.

García Añoveros, J. M. (1987b). Pedro de Alvarado. Madrid, España: Ediciones Quorum. González de Barcía Carballido y Zúñiga, A. (1749). Historiadores primitivos de las Indias Occidentales: que juntó, traduxo en parte, y sacò à luz, ilustrados por erudìtas Notas, y copiosos Índices (Tomo I). Madrid, España. https://hdl.handle.net/2027/hvd.hx2z29

Juárez Blanquer, A. y Rubio Flores, A. (1991). Introducción. En A. Juárez Blanquer y A. Rubio Flores (Eds.), Partida segunda de Alfonso X El Sabio: Manuscrito 12794 de la B. N. (pp. 7-31). Granada, España: Impredisur.

Kramer, W., Lovell, G. y Lutz, C. (1993). La conquista española de Centroamérica. En J. C. Pinto Soria (Ed.), Historia general de Centroamérica: El régimen colonial (15241750) (Tomo II). Madrid, España: Sociedad Estatal Quinto Centenario / Facultad Latinoamericana de Ciencias Sociales.

Kruger Hickman, K. (1987). Literary Strategies of Persuasion in the Cartas-relaciones of Hernán Cortés. San Diego, EE. UU.: University of California.

Leonard, I. A. (1949). Books of the Brave: Being an Account of Books and of Men in the Spanish Conquest and Settlement of the Sixteenth Century. Cambridge, MA: Harvard University.

López de Gómara, F. (1979). Historia general de las Indias y vida de Hernán Cortés. Caracas, Colombia: Biblioteca Ayacucho.

Lovell, G. y Christopher Lutz, C. (2001). Pedro de Alvarado and the Conquest of Guatemala, 1522-24. En J. M. Weeks (Ed.), The Past and Present Maya: Essays in Honor of Robert M. Carnack (pp. 47-61). Lancaster, EE. UU.: Laberynthos. 
Magaña Morton, E. (2009). Literatura colonial: Pedro de Alvarado. El Conquistador en el Nuevo Mundo: Su identidad reflejada por escritores contemporáneos y por sus propios escritos. [Tesis doctoral, Universidad de Alabama. ProQuest Dissertations \& Theses Global]. https://weblogin.bu.edu//web@login3?jsv=1.5p\&br=un\&fl=0

Mazzotti, J. A. (2011). Mezquitas, agravios y traiciones: sobre el discurso caballeresco en las crónicas de la conquista. En P. Latasa (Ed.), Discursos coloniales: texto y poder en la América hispana (pp. 101-127). Madrid, España: Iberoamericana / Vervuert.

Mazzotti, J. A. (2017). Barataria desde los estudios andinos: utopía y Perú en el Quijote. En K. Beauchesne y A. Santos (Eds.), The Utopian Impulse in Latin America (pp. 5170). Basingstoke, Inglaterra: Palgrave Macmillan.

Mignolo, W. (1981). El Metatexto Historiografico y la Historiografia Indiana. MLN, 96(2), 358-402. https://doi/10.2307/2906354

Mignolo, W. (1982).Cartas, crónicas y relaciones del descubrimiento y la conquista. En L. Íñigo Madrigal (Coord.), Historia de la literatura hispanoamericana: Tomo I. Época colonial (pp. 57-116). Madrid, España: Cátedra.

Moll, J. (2000). La imprenta manual. En F. Rico (Dir.), Imprenta y crítica textual en el Siglo de Oro (pp. 13-27). Valladolid, España: Secretaría de Publicaciones e Intercambio Científico Universidad de Valladolid / Centro parala Edición de los Clásicos Españoles.

Oesterreicher, W. (1994). El español en textos escritos por semicultos. Competencia escrita de impronta oral en la historiografía inidana. En J. Lüdtke (Comp.), El español de América en el siglo XVI: Actas del Simposio del Instituto Ibero-Americano de Berlín, 23 y 24 de abril de 1992 (pp. 155-190). Madrid, España: Vervuert / Iberoamericana. 
Oesterreicher, W. (2004). Textos entre inmediatez y distancia comunicativas. El problema de lo hablado escrito en el Siglo de Oro. En R. Cano (Ed.), Historia de la lengua española (pp. 729-769) Barcelona, España: Ariel.

Restall, M. y Asselbergs, F. (2007). Invading Guatemala: Spanish, Nahua, and Maya Accounts of the Conquest Wars. Pennsylvania, EE. UU.: The Pennsylvania State University Press.

Rodríguez Prampolini, I. (1948). Amadises de America: La hazaña de Indias como empresa caballeresca. México: Junta Mexicana de Investigaciones Históricas.

Schmidt Riese, R. (2003). Relatando México: Cinco textos del periodo fundacional de la colonia en Tierra Firme. España: Vervuert / Iberoamericana.

Serrano Montesinos, M. J. (2014). El sujeto y la subjetividad: Variación del pronombre ‘yo’ en géneros conversacionales y de los medios de comunicación del español de Canarias. Revista signos: estudios de lingüística, 47(85), 321-343. https://doi/10.4067/S0718-09342014000200008.

Simón Díaz, J. (1973). Bibliografía de la literatura hispánica: Tomos V Y VI. Madrid, España: Consejo Superior de Investigaciones Científicas.

Tenorio, M. (2002). Beber, comer, fornicar: El cuerpo de Pedro de Alvarado en papeles relativos a la conquista de Guatemala y El Salvador, 1524 y 1529. Istmo: Revista virtual de estudios literarios y culturales centroamericanos, $4, \quad$ s. $\quad$ p. http://istmo.denison.edu/n04/proyectos/alvarado.html

Valero Silva, J. (1954). Introducción. En P. Alvarado (1954). Relación hecha por Pedro de Alvarado a Hernán Cortés, en que se refieren las guerras y batallas para pacificar 
las provincias del antiguo reino de Goathemala (pp. 7-19). Estudio y notas de José Valero Silva. México: José Porrúa e Hijos.

Vallejo García Hevia, J. M. (2008). Juicio a un conquistador, Pedro de Alvarado: su proceso de residencia en Guatemala, 1536-1538. Transcripción documental por Julio Martín Blasco (2 vols.). Madrid, España: Marcial Pons Historia.

Vedia, E. (Dir.). (1852). Historiadores primitivos de Indias. (Tomo I). Madrid, España: M. Rivadeneyra. https://babel.hathitrust.org/cgi/pt?id=nyp.33433081690277

Zavala, S. (1947). Filosofía de la conquista. México: Fondo. 